\title{
Experimental Study of Three-Bed Adsorption Chiller with Desalination Function
}

\author{
Karol Sztekler ${ }^{1, * \mathbb{C}}$, Wojciech Kalawa ${ }^{1}$, Wojciech Nowak ${ }^{1}$, Lukasz Mika ${ }^{1}$, \\ Slawomir Gradziel ${ }^{2}$, Jaroslaw Krzywanski ${ }^{3}\left(\mathbb{D}\right.$ and Ewelina Radomska ${ }^{1}$ (D)
}

1 Department of Thermal and Fluid Flow Machines, Faculty of Energy and Fuels, AGH University of Science and Technology, Mickiewicza 30 St., 30-059 Krakow, Poland; kalawa@agh.edu.pl (W.K.); wnowak@agh.edu.pl (W.N.); lmika@agh.edu.pl (L.M.); radomska@agh.edu.pl (E.R.)

2 Department of Energy, Faculty of Environmental Engineering and Energy, Cracow University of Technology, Jana Pawla II 37 St., 31-864 Cracow, Poland; gradziel@mech.pk.edu.pl

3 Faculty of Science and Technology, Jan Dlugosz University in Czestochowa, A. Krajowej 13/15, 42-200 Czestochowa, Poland; j.krzywanski@ujd.edu.pl

* Correspondence: sztekler@agh.edu.pl

Received: 6 October 2020; Accepted: 6 November 2020; Published: 8 November 2020

\begin{abstract}
Energy efficiency is one of the most important topics nowadays. It is strictly related to energy demand, energy policy, environmental pollution, and economic issues. Energy efficiency can be increased and operating costs reduced by using waste heat from other processes. One of the possibilities is to use sorption chillers to produce chilled water and desalinated water. Low-temperature waste heat is not easy to utilize because of the low energy potential. Using adsorption chillers in low-temperature conditions allows utilizing waste heat and producing useful products in many regions of the world. The paper presents the results of an experimental study carried out on a three-bed adsorption chiller with desalination function, using silica gel and water as a working pair. The laboratory test stand included one evaporator, one condenser, and three separate tanks for water, desalinated water, and brine, respectively. The test stands scheme and description were presented. All results were obtained during several test hours with stable temperature conditions in the range of $57-85^{\circ} \mathrm{C}$ for the heating water. It is found that the Coefficient of Performance (COP) increased from 0.20 to 0.58 when the heating water temperature increased from 57 to $85^{\circ} \mathrm{C}$. A similar finding is reported for Specific Cooling Power (SCP), which increased from 27 to $160 \mathrm{~W} / \mathrm{kg}$ as the heating water temperature increased from 57 to $85^{\circ} \mathrm{C}$. It can be concluded that the heating water temperature strongly impacts the performance of the adsorption chiller.
\end{abstract}

Keywords: adsorption chiller; coefficient of performance; desalination; energy efficiency; low-temperature heat; silica gel; specific cooling power; waste heat recovery

\section{Introduction}

The dynamic development of the economy and industrialization in the nineteenth and twentieth century was associated with higher energy consumption, which resulted in an increasing demand for fossil fuels, especially bituminous coal and lignite. However, burning more fossil fuels has caused various ecological and environmental issues, which people have been trying to solve since recent years. One of the instruments to reduce the negative impact of burning fossil fuels on the environment are numerous European Union directives regarding climate protection. These directives concern, for example, the reduction of greenhouse gas emissions, supporting the development of renewable energy and low-carbon technologies, as well as the Emissions Trading System [1]. Similar efforts are also carried out at the global level, as exemplified by the Paris Agreement adopted at the Paris Climate 
Conference (COP21) in December 2015 [2], and the 24th Conference of the Parties to the United Nations Framework Convention on Climate Change (COP24) at Katowice in 2018 [3]. The main aims of the agreements made during the conferences mentioned above are reducing energy and natural resources consumption and minimizing the level of pollution emitted to the environment.

According to the Energy Statistics in 2016 and 2017 [4], the global consumption of total energy in Poland in 2017 was 4410 PJ, while the energy consumption by households (including energy consumption by cars) was 1146 PJ, which accounted for approximately $26 \%$ of the global consumption of total energy in Poland. In Poland in 2016, the global consumption of total energy and the energy consumption by households (including energy consumption by cars) was 4216 and 1142 PJ, respectively. Furthermore, the energy consumption forecast prepared by Agencja Rynku Energii S.A. [5] indicates the growth of the total primary energy demand and the electricity demand in 2030 by $27 \%$ and $54 \%$, respectively, compared to the demand in 2010. It is worth mentioning that electricity consumption by air conditioning and refrigeration systems is one of the factors that significantly contributes to the overall electricity consumption growth. Refrigeration has been developing dynamically since the nineteenth century due to its application in numerous fields, including production, transport and food storage, industry (the necessity of cooling various devices and machines), air conditioning of buildings, household refrigerators, etc. Additionally, more and more rigorous legal regulations concerning environmental protection, e.g., Regulation (European Union) No. 517/2014 of the European Parliament and of the Council of 16 April 2014, on fluorinated greenhouse gases and repealing Regulation (European Commission) No. 842/2006 [6], are being introduced. Therefore, searching for new possibilities for refrigeration systems development seems to be unavoidable.

The technology that meets the challenges of legal regulations and environment protection turned out to be adsorption refrigeration systems. The adsorption refrigerators are a more promising and attractive field for research than conventional electrically-driven vapor compression chillers, since the adsorption systems do not use undesirable chlorofluorocarbons that cause ozone depletion. Substances, e.g., water, used as refrigerants in the adsorption chillers, are environmentally friendly and do not cause ozone depletion [7].

The refrigeration cycles' working principle in adsorption chillers with water as a refrigerant is based on the sorbent's hygroscopic properties, which is a non-toxic substance. The sorbent adsorbs water vapor in the adsorption bed due to the electrostatic attraction and van der Waals forces. A silica-gel, aluminum fumarate, and ferro-aluminophospate can be used as sorbents [8]. Regardless of the sorbent used, heat must be supplied to the saturated sorbent to release the adsorbed water after the adsorption process. Thus, the adsorption chillers use heat to operate, unlike vapor compression chillers that use electricity to operate. The sources of the above mentioned heat include:

- Warm water from a district heating system [9];

- Direct burning of fossil fuels, e.g., gas [9];

- Waste heat from exhaust gases [9];

- Waste heat from power plants or combined heat and power systems [9];

- Renewable energy, especially solar energy [10].

Furthermore, adsorption chillers possess additional advantages over electrically-driven vapor compression chillers, such as the possibility of using water as a refrigerant [10,11], low level of noise, lack of vibrations, and lack of moving parts [9]. Adsorption chillers might be applied wherever the heat in the temperature range of $60-75{ }^{\circ} \mathrm{C}$ or a steam in the pressure range of $1-8$ bar is available. Nevertheless, adsorption chillers possess a low Coefficient of Performance (COP), not exceeding approximately 0.6 [11], compared to vapor compressor chillers whose COP might be as high as 6 [12]. As a result, many methods of increasing the COP have been investigated. For example, Shabir et al. [13] investigated the COP of the adsorption chiller with different adsorbent/refrigerant pairs. It was found that among the investigated pairs (KOH6-PR/ethanol, WPT-AC/ethanol, Maxsorb-III/methanol, Maxsorb-III/CO $/ \mathrm{CO}_{2}$ Maxsorb-III/n-butane, Maxsorb-III/R-134a, SAC-2/R32, and Maxsorb-III/R507a), 
the Maxsorb-III/methanol pair showed the highest COP. Uyun et al. [14] applied the internal heat recovery in the investigated adsorption chiller. The COP of the improved chiller increased by $13.4 \%$ compared to the COP of the chiller without heat recovery. Chorowski et al. [15] found that the chiller's COP can be raised by $7.5 \%$ by modifying only the control system, i.e., switching time and cycle allocation.

In addition to the low COP of adsorption chillers, a cyclic operation resulting in an irregular cold production is their significant drawback [16]. Thus, several (two, three, or more) sub-processes are working alternately, obtaining a quasi-continuous cooling capacity [17-19]. Two-bed and four-bed adsorption chillers have gained much attention in the scientific community in the last years. For example, Pan et al. [20] experimentally investigated the influence of the heating water temperature on the two-bed adsorption chiller's performance. Woo et al. [21] also examined the two-bed adsorption chiller's performance under different operating conditions, but their chiller possessed another water desalination function. Similar studies were conducted by Kim et al. [22], who investigated the water quality produced in the four-bed adsorption chiller. On the other hand, there are only a few studies concerning three-bed adsorption chillers in the literature. Saha et al. [23], who experimentally investigated the three-bed adsorption chiller's performance, reported that its Coefficient of Performance (COP) increased from approximately 0.28 to 0.38 when the heating water temperature increased from 60 to $90{ }^{\circ} \mathrm{C}$. A slightly greater COP, i.e., 0.64 , of the three-bed adsorption chiller was obtained by Chorowski and Pyrka [24]. Furthermore, it was concluded that the three-bed application allows chillers to work more effectively compared to two-bed chillers.

This paper presents the results of an experimental study on the influence of the heat source temperature on the Specific Cooling Power (SCP) and the COP of the three-bed adsorption chiller with desalination function, in which two beds work in parallel while the third bed works individually. The present work is the first in the literature dealing with the presented approach, i.e., two beds working in parallel and the third bed working individually, in the considered three-bed adsorption chiller. Water in the temperature range of $57-85^{\circ} \mathrm{C}$ was used as a heat source for bed regeneration during the desorption process. Based on the literature review presented in the paragraphs above, it seems that the research on the three-bed adsorption chiller is necessary and justified due to the following reasons: Three-bed chillers are supposed to work more efficiently than two-bed chillers, but they are less complicated and require fewer elements than four-bed chillers. Furthermore, the three-bed adsorption chiller investigated in this work has the water desalination function, and to the best of the authors' knowledge, an experimental study on such a chiller has not been done before.

\section{Materials and Methods}

\subsection{Experimental Setup}

The study's base is the three-bed adsorption chiller, located in the Center of Energy at the AGH University of Science and Technology in Cracow, Poland. The simplified diagram and the pictures of the investigated three-bed adsorption chiller are shown in Figures 1 and 2, respectively, while Table 1 contains the chiller's main parameters. The investigated adsorption chiller can operate in two modes, i.e., cooling mode and water desalination mode. Additionally, the chiller can work in the two-bed as well as three-bed mode. The considered three-bed adsorption chiller comprises three beds as the efficiency, in terms of maximizing the cooling capacity and reducing the chilled water outlet temperature fluctuations, of such devices is higher than one with one or two adsorption beds [25]. For example, increasing the number of chiller's beds from two to four can improve efficiency by 70\% [25]. Moreover, such an adsorption chiller provides additional functionality to conduct different operational strategies and divide adsorption and desorption processes between different beds. Independently from the operating modes, water and silica gel are used as refrigerant and adsorbent, respectively. 


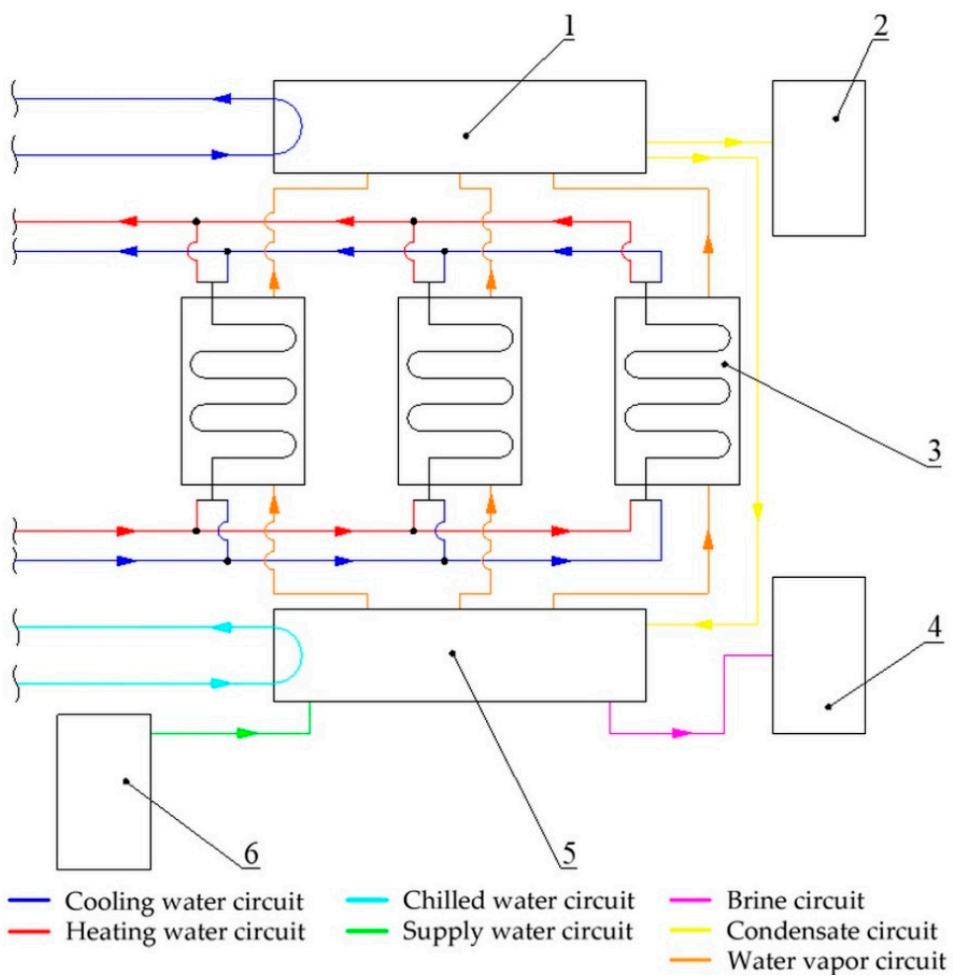

Figure 1. The simplified diagram of the investigated adsorption chiller with desalination function. 1-condenser; 2-distillate tank; 3-adsorbent bed; 4-brine tank; 5-evaporator; 6-deaerator.

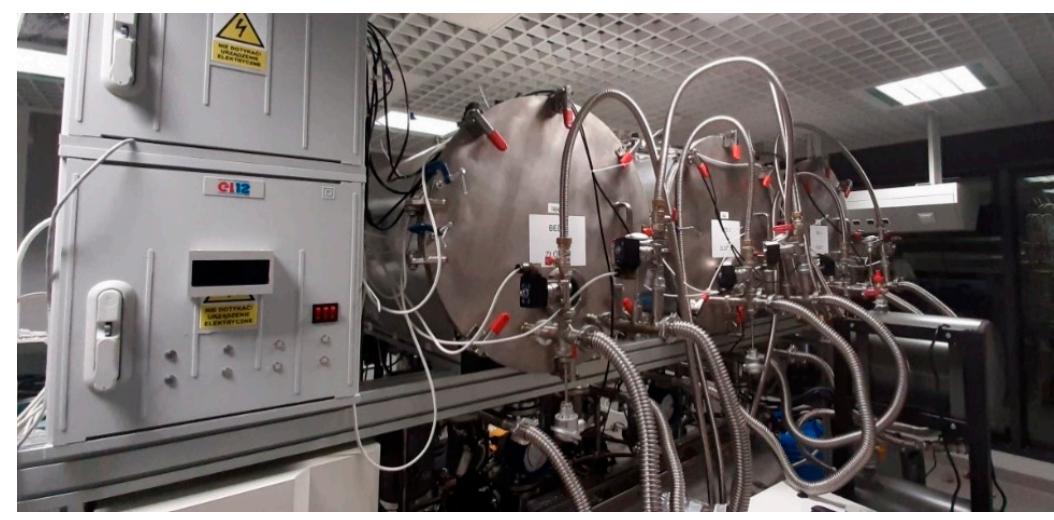

(a)

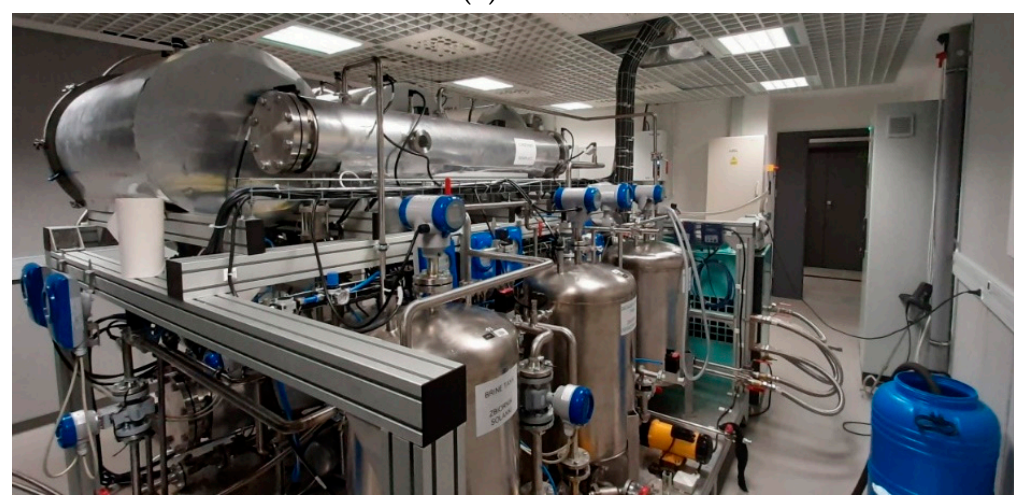

(b)

Figure 2. The picture of the investigated adsorption chiller with desalination function: (a) Front view, (b) back view. 
Table 1. The nominal main parameters of the adsorption chiller.

\begin{tabular}{cccc}
\hline & Parameter & Value & Unit \\
\hline \multirow{4}{*}{ Evaporator } & Cooling capacity & 1.10 & $\mathrm{~kW}$ \\
& The chilled water inlet temperature & 12 & ${ }^{\circ} \mathrm{C}$ \\
& The chilled water outlet temperature & 7 & ${ }^{\circ} \mathrm{C}$ \\
& The chilled water mass flow & 0.052 & $\mathrm{~kg} / \mathrm{s}$ \\
\hline \multirow{5}{*}{ Condenser } & Capacity & 2.00 & $\mathrm{~kW}$ \\
& The cooling water inlet temperature & 20 & ${ }^{\circ} \mathrm{C}$ \\
& The cooling water outlet temperature & 22 & ${ }^{\circ} \mathrm{C}$ \\
& The cooling water mass flow & 0.250 & $\mathrm{~kg} / \mathrm{s}$ \\
& Daily distillate production & 40 & $\mathrm{~kg}$ \\
\hline
\end{tabular}

The investigated adsorption chiller consisted of six main elements: Condenser (marked with number 1 in Figure 1), distillate tank (2), adsorbent bed (3), brine tank (4), evaporator (5), and deaerator (6). Saline water (marked with green in Figure 1) from the deaerator flowed to the evaporator. Simultaneously, the chilled water flowed through the evaporator and transferred heat to the saline water. As a result, the saline water evaporated, and the chilled water temperature decreased, thereby obtaining a beneficial cooling effect. The saline water's evaporation at low temperature was possible due to a very low absolute pressure in the evaporator. Then, the water with high salinity, called brine (marked with purple in Figure 1), was pumped to the brine tank, while the evaporated water went to the adsorbent beds and the adsorption phase started. It should be noted that the operating mode of the investigated adsorption chiller for the needs of the experiment was set to three-bed. Hence, beds number one and two worked in parallel, while bed number three worked individually. It means that the adsorption took place simultaneously in beds number one and two, while at the same time, the desorption process was carried out in bed number three. Similarly, when the desorption was in beds number one and two, the adsorption was in bed number three. Nevertheless, the adsorption is an exothermic process, and the cooling water (marked with dark blue in Figure 1) dissipated the heat generated during the adsorption, as well as condensation. This phase ended when the cooling water reached the required temperature. After the adsorption/desorption phase, the three-way valves were adjusted so that the heating water (marked with red color in Figure 1) was flowing through the adsorber until the water reached a required temperature. That phase was called preheating, and the heating water was produced by using the electric water boiler with a power of $18 \mathrm{~kW}$. After the preheating, the desorption phase started. During the desorption, the heating water flowed through the beds. As a result, the water collected earlier at the silica gel's surface was desorbed, its pressure increased, and in a gaseous state flowed to the condenser where it was condensed. The cooling water dissipated the heat of condensation. The part of the condensate (marked with yellow in Figure 1) collected in the bottom part of the condenser was transported to the evaporator through an expansion valve, while the other part was transported to the distillate tank, obtaining a useful distillate. The expansion valve function, which is not included in Figure 1, was to keep the pressure difference between the condenser and the evaporator. After the desorption phase, the heat recovery started. The three-way valves were adjusted so that the cooling water flowed through the adsorber, which was desorbed during the earlier phase. Heat accumulated in the adsorber was not dissipated immediately, but it was transported for some time to the heating water circuit.

As mentioned at the beginning of this section, the chiller can operate in the cooling mode and desalination mode, wherein these modes are simultaneous usually. The desalination mode is active when the saline water supplies the evaporator. The water evaporates but the salt does not, and the so-called brine that remained in the evaporator is pumped to the brine tank. The evaporated water goes to the condenser after the processes described in the previous paragraph. Finally, the water vapor condenses in the condenser, and the useful desalinated water, called distillate, is collected in 
the distillate tank. However, the experiments did not focus on the desalination mode, but on the cooling mode.

\subsection{Measuring Devices and Data Acquisition System}

The pressures, temperatures, and flow rates were measured during the experiment. The measuring devices and their main parameters are collected in Table 2. The PT-1000 sensors were used to measure the beds' temperatures, evaporator, condenser, inlet, and outlet temperatures of the cooling water, heating water, and chilled water. Pressure transducers measured the pressure in the condenser, evaporator, and beds. Electromagnetic flow meters measured the flow rates of the heating water, cooling water, and chilled water.

Table 2. Measuring devices and their main parameters.

\begin{tabular}{cccc}
\hline Measured Value & Measuring Device & Range & Accuracy \\
\hline Temperature & Pt-1000 sensor & -80 to $150{ }^{\circ} \mathrm{C}$ & $\pm 0.1{ }^{\circ} \mathrm{C}$ \\
Pressure & Pressure transducer & 0 to $99 \mathrm{kPa}$ & $\pm 0.5 \%$ \\
Flow rate & Electromagnetic flow meter & $1-100 \mathrm{~L} / \mathrm{min}$ & $\pm 0.5 \%$ \\
\hline
\end{tabular}

All of the measuring devices and measuring transducers were power-supplied from the switchgear fixed to the experimental setup supporting structure. The instrumentation, control, and automation section was equipped with a programmable logic controller. The appropriate software of the control system allowed controlling the pumps and valves, setting the duration time of each phase, as well as recording the measured values. The measured values were recorded every $5 \mathrm{~s}$ using the SCADA control system and a personal computer. The obtained data were exported in a tabular form in csv format, which allowed for analysis of the collected data. The analysis of the obtained data was done using Microsoft Excel.

All test stand's elements were thoroughly inspected. The measurements were made after the refrigerator was started and its working parameters stabilized. The stabilization time of the chiller's parameters was about $1 \mathrm{~h}$.

\subsection{Operating Conditions}

Experimental studies were carried out to optimize the adsorption chiller's critical parameters, influencing its performance and efficiency. During the experiments, beds number one and two worked in parallel during both adsorption and desorption phases, while bed number three worked individually. Only one configuration of the sequences was used, and the duration time of each phase was determined on an individual basis. The duration time of each phase is presented in Table 3.

Table 3. The time of each phase.

\begin{tabular}{cc}
\hline Chiller Operation Phase & Time, (s) \\
\hline Preheating & 50 \\
Adsorption/desorption & 170 \\
Heat recovery & 30 \\
\hline
\end{tabular}

As shown in Table 3, the total time of the device's operation cycle in the automatic mode consists of preheating time, desorption time, heat recovery time, and desorption time. Thus, the total time of the full working cycle is $420 \mathrm{~s}$ in the case of the investigated chiller. The desorption and adsorption of each bed are preceded by preheating and heat recovery, respectively, which is necessary for the proper operation of the device. However, the preheating and heat recovery extend the total time of the full cycle of each bed by $80 \mathrm{~s}$, which is $23.5 \%$ of the one full cycle and may influence the coefficient of performance. As commonly known, the desorption is approximately 2 times faster than 
the adsorption, hence, the alternately-working beds are intentional. The parallel work of beds number one and two allows saving the preheating and heat recovery time in one bed since these processes are simultaneous in the investigated chiller. This should improve the three-bed adsorption chiller's coefficient of performance compared to the two-bed adsorption chiller within a certain heating water temperature range.

The experimental studies were carried out to investigate the influence of the heating water temperature used to regenerate the bed during the desorption on the Coefficient of Performance (COP), Specific Cooling Power (SCP), average evaporator temperature, average evaporator pressure, and average chilled water temperature. The beds' pressure and the average temperature of the evaporator, condenser, and beds, were also analyzed. The COP and SCP were calculated according to the formulas given in [26], which are presented below:

$$
\begin{gathered}
\mathrm{COP}=\frac{\mathrm{CC}}{\mathrm{HP}^{\prime}} \\
\mathrm{CC}=\dot{\mathrm{m}}_{\mathrm{c}} \cdot \mathrm{c}_{\mathrm{p}, \mathrm{c}} \cdot\left(\mathrm{T}_{\mathrm{i}, \mathrm{c}}-\mathrm{T}_{\mathrm{O}, \mathrm{c}}\right), \\
\mathrm{HP}=\dot{\mathrm{m}}_{\mathrm{h}} \cdot \mathrm{c}_{\mathrm{p}, \mathrm{h}} \cdot\left(\mathrm{T}_{\mathrm{i}, \mathrm{h}}-\mathrm{T}_{\mathrm{o}, \mathrm{h}}\right), \\
\mathrm{SCP}=\frac{\mathrm{CC}}{\mathrm{m}_{\mathrm{a}}},
\end{gathered}
$$

The symbols used in Equations (1)-(4) correspond to: CC—cooling capacity, (W); HP—heating power supplied to the system, $(\mathrm{W}) ; \dot{\mathrm{m}}-$ flow rate, $(\mathrm{kg} / \mathrm{s}) ; \mathrm{c}_{\mathrm{p}}$ - specific heat of water, which was assumed to be $4200 \mathrm{Jkg}^{-1} \mathrm{~K}^{-1}$; T-temperature, $\left({ }^{\circ} \mathrm{C}\right) ; \mathrm{m}_{\mathrm{a}}$ - the mass of sorbent, which was $12 \mathrm{~kg}$. Additionally, the subscripts $\mathrm{c}, \mathrm{h}, \mathrm{i}$, and o correspond to chilled water, heating water, inlet, and outlet, respectively. The SCP determines the cooling capacity obtained from $1 \mathrm{~kg}$ of the sorbent. Additionally, the COP of the investigated three-bed adsorption chiller was compared with the COP of the two-bed adsorption chiller investigated by Sztekler et al. [26].

The heating water temperature was changed in the range of $57-85^{\circ} \mathrm{C}$. The cooling water was used to dissipate the heat from the condenser and beds, and its inlet temperature was $20^{\circ} \mathrm{C}$. The maximum temperature difference between the outlet and inlet cooling water from the condenser was approximately $2{ }^{\circ} \mathrm{C}$. The adsorption chiller produced chilled water. The chilled water's outlet temperature varied from 8 to $16^{\circ} \mathrm{C}$, with a maximum temperature difference between the inlet and outlet temperature of $2.5^{\circ} \mathrm{C}$. The mass flow of each water circuit was constant during the experiments.

\section{Results and Discussion}

The experimental studies focused on the impact of heating water temperature, which varied in the range of $57-85^{\circ} \mathrm{C}$, on the three-bed adsorption chiller's main operating parameters. The results show that changing the temperature of heating water strongly influences the COP and SCP of the chiller with two beds working in parallel and one bed working individually, as presented in Figures 3 and 4, respectively. When the heating water temperature increased from 57 to $85^{\circ} \mathrm{C}$, the COP increased by $190 \%$ (from 0.20 to 0.58 ).

The COP of the investigated chiller, in this work the three-bed adsorption chiller, is difficult to be compared to the COP of the other chillers investigated by the other researchers, since the COP is influenced by many factors, including the beds' construction, capacity, and material. Therefore, the three-bed adsorption chiller's COP obtained in this work is compared only to the COP of the same chiller but working in a two-bed mode, as investigated in the authors' previous study [26]. It should be noted that the temperatures of chilled and cooling water in the case of the two-bed adsorption chiller were 13 and $18{ }^{\circ} \mathrm{C}$, respectively, which is almost the same as in the case of the three-bed chiller.

As can be seen in Figure 3, the three-bed chiller's COP increased by about $190 \%$ when the heating water temperature increased from 57 to $85^{\circ} \mathrm{C}$. Similarly, the SCP, which determines the cooling capacity obtained from $1 \mathrm{~kg}$ of the sorbent, increased from 27 to $160 \mathrm{~W} / \mathrm{kg}$ when the heating water temperature 
was increased from 57 to $85^{\circ} \mathrm{C}$. Additionally, for the heating water temperature above $75^{\circ} \mathrm{C}$, the COP of the considered three-bed adsorption chiller is higher by the maximum value of about $16 \%$ than the two-bed adsorption chiller's COP investigated in the previous work [26]. This confirms that the three-bed adsorption chiller performance in temperatures above $75^{\circ} \mathrm{C}$ is higher than the chiller with two adsorption beds. On the other hand, the three-bed chiller's COP (two beds working in parallel and one bed working individually) is lower compared to the two-bed chiller's COP for the heating water temperature below $75^{\circ} \mathrm{C}$. A possible explanation of such a result is most likely due to a low heat transfer rate caused by a small temperature difference between the heating water and beds. As a result, a power shortage occurs in each chiller's element, especially in the evaporator, which is enhanced in the three-bed chiller due to an increased number of beds and larger sorbent mass.

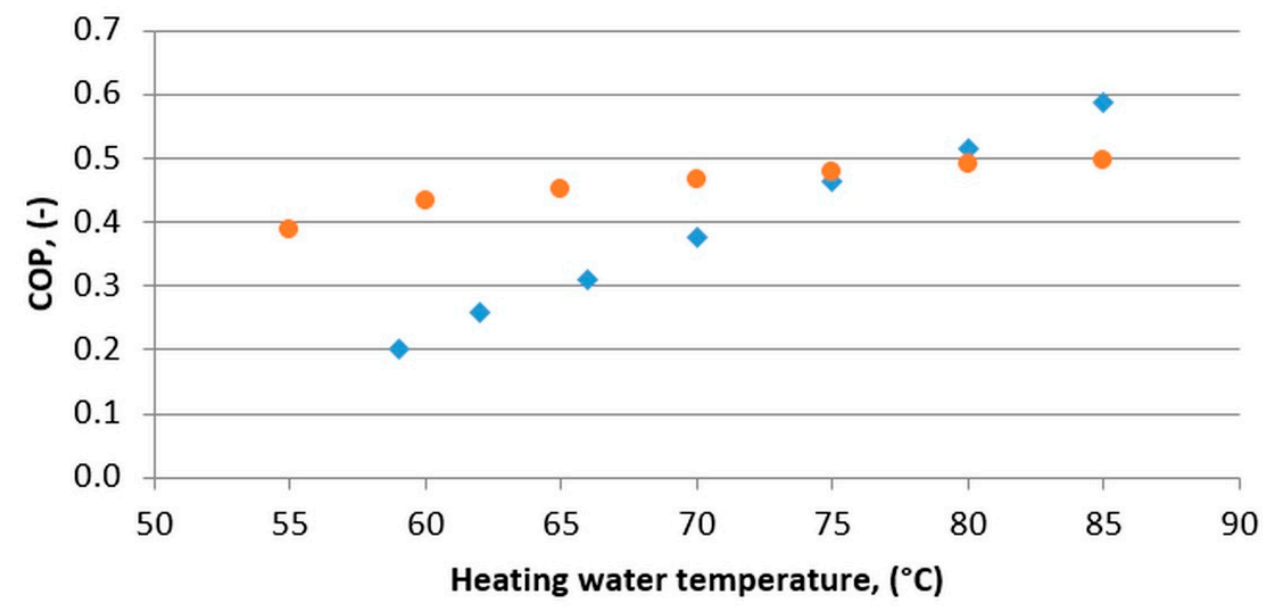

Three-bed adsorption chiller with parallelly working beds - current work
- Two-bed adsorption chiller - previous work [26]

Figure 3. The influence of the heating water temperature on the coefficient of performance (COP).

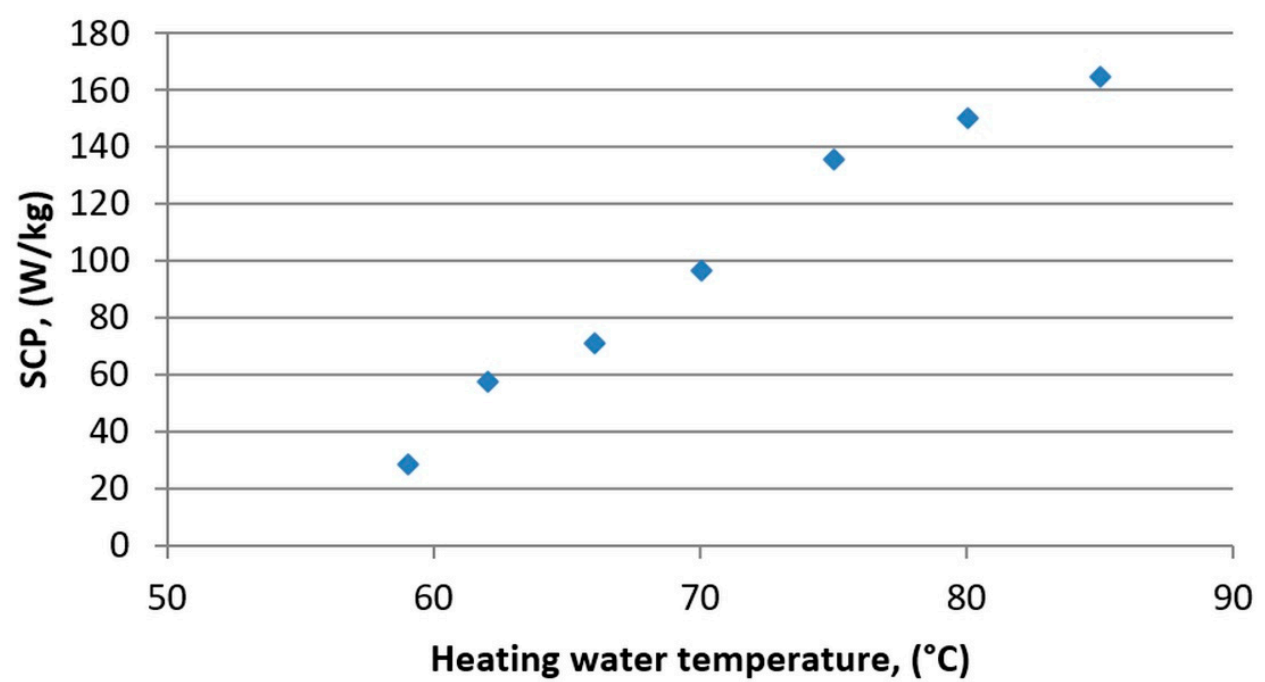

Figure 4. The influence of the heating water temperature on the specific cooling power (SCP).

The experiments' results indicate the strong influence of the heating water temperature on the COP and SCP. As the heating water temperature increased, both the COP and SCP rose due to a more intense water release from the silica gel and faster desorption process. The heating water temperature increment shortened the desorption time and accelerated the regeneration of the bed. As a 
result, more water from the evaporator was adsorbed by the sorbent. Consequently, the evaporator's cooling capacity increased, and the generated chilled water's temperature decreased, which is shown in Figure 5. The chilled water mass flow rate was constant during the experiments, and when the heating water temperature increased from 57 to $85^{\circ} \mathrm{C}$, the chilled water temperature decreased from approximately 16 to $10^{\circ} \mathrm{C}$. This means that the chilled water temperature decreased by $6{ }^{\circ} \mathrm{C}$ while maintaining a constant mass flow rate through the evaporator.

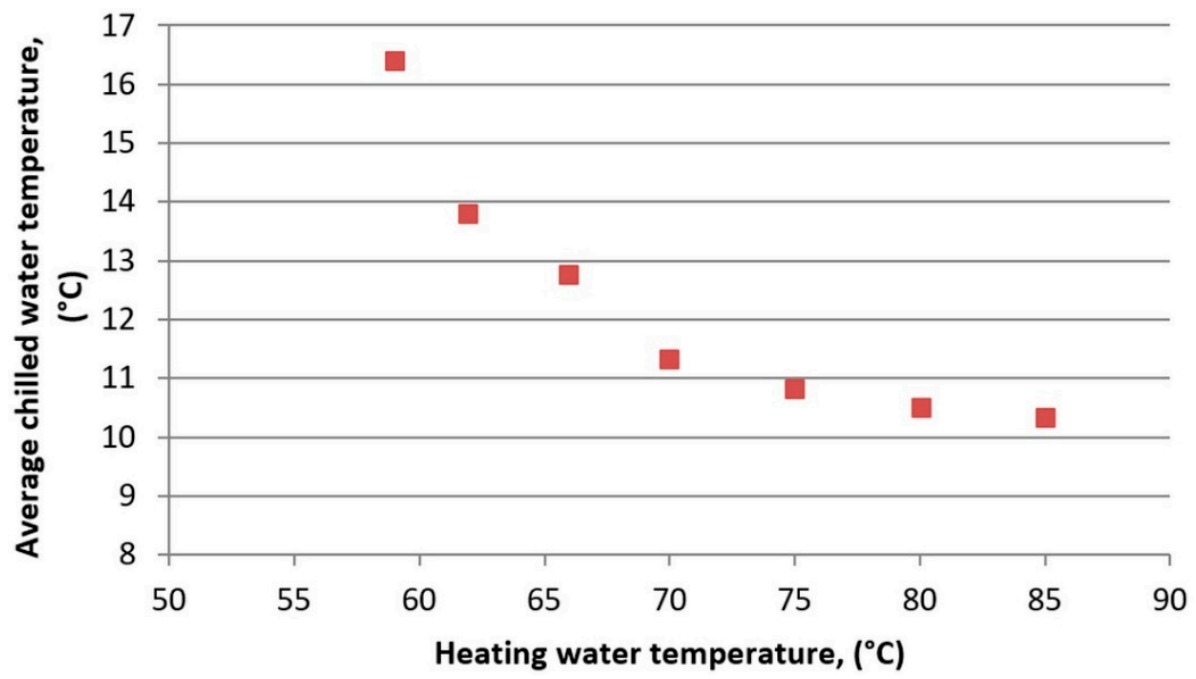

Figure 5. The influence of the heating water temperature on the average chilled water temperature.

The chilled water temperature drop caused by increasing the heating water temperature was related to the increment of the adsorbent sorption properties. As a result, the average evaporator pressure and the average evaporator temperature decreased, which is shown in Figure 6. As can be seen, the average evaporator pressure and the average evaporator temperature were $2 \mathrm{kPa}$ and $16^{\circ} \mathrm{C}$, respectively, when the heating water temperature was $57^{\circ} \mathrm{C}$. As the heating water temperature increased to $85^{\circ} \mathrm{C}$, the average evaporator pressure and the average evaporator temperature decreased to $1.05 \mathrm{kPa}$ and $7{ }^{\circ} \mathrm{C}$, respectively. The evaporator temperature changes were a result of the processes in the chiller related to the adsorption/desorption of water vapor in the silica-gel in the beds.

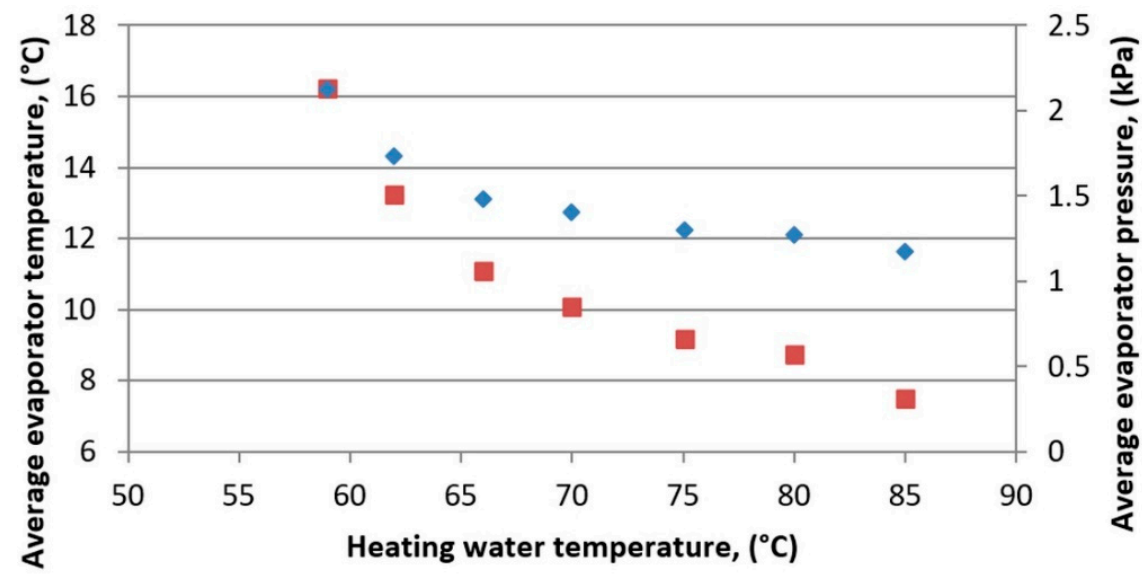

Average evaporator temperature $\quad$ Average evaporator pressure

Figure 6. The influence of the heating water temperature on the average evaporator temperature and the average evaporator pressure. 
As mentioned before, the heating water temperature was changed in the range of $57-85^{\circ} \mathrm{C}$. As shown in Figure 7, the temperature changes of beds are uniform, and the temperature changes resulted from the alternating adsorption/desorption processes. Additionally, when the heating water temperature decreased, the beds' temperatures decreased from 70 to $50{ }^{\circ} \mathrm{C}$ during the desorption. Moreover, for low heating water temperatures, the bed working individually heated up and cooled down faster than the two beds working in parallel. Moreover, as the heating water temperature decreased, the evaporator temperature increased, which indicates a low heat transfer rate from the evaporator to the water, and confirms a less intensive beds' operation. It is worth noting that the beds' temperatures were measured inside the heat exchanger, between the silica gel and the heat exchanger pipes, and manual settings set the time of the adsorption phases. The evaporator temperature increased from 7 to $16^{\circ} \mathrm{C}$ when the heating water temperature decreased. On the other hand, the condenser temperature was constant, independently from the heating water temperature.
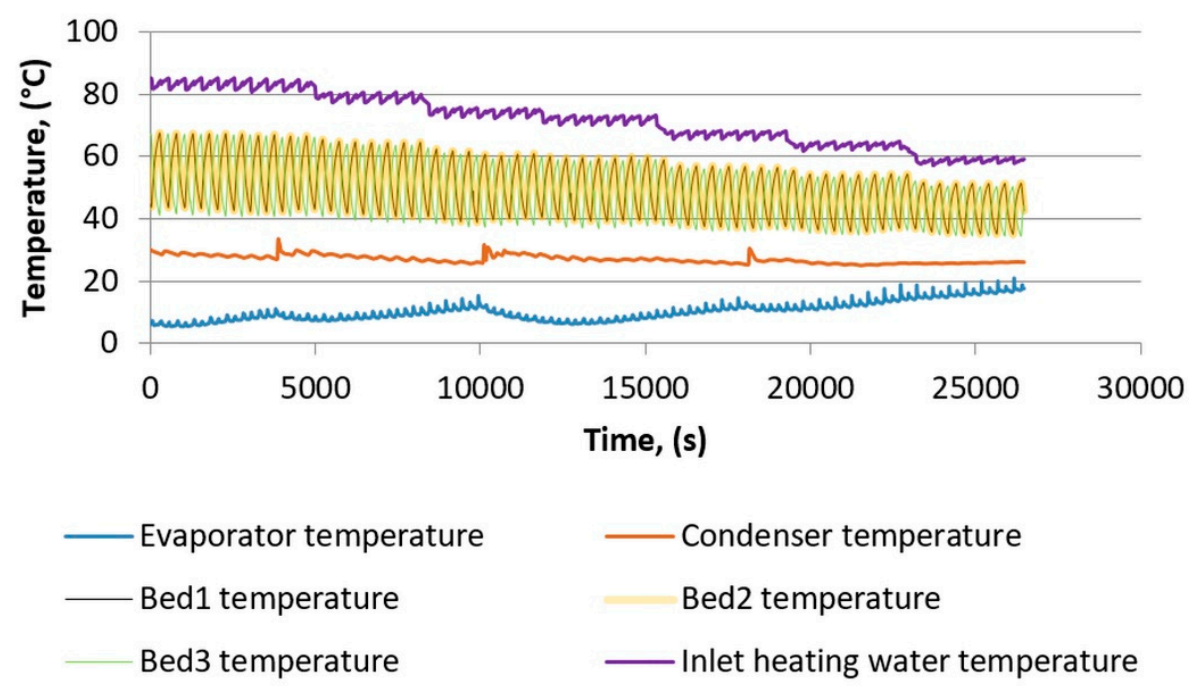

Figure 7. The changes in the evaporator, condenser, and bed temperatures in the function of time.

Figure 8 presents the beds' pressure in the function of time during the adsorption/desorption cycles. The results show that bed number one and bed number two worked in a parallel arrangement, which means they worked simultaneously during the adsorption/desorption phase, as explained in Section 2.1. Bed number three worked in a singular arrangement during the different working phases. The pressure changes in the beds reflect the operating cycle of the adsorption chiller. When the water vapor flows between the evaporator and the bed during the adsorption phase, the system is trying to equalize the pressure between the evaporator and bed. The pressure in the beds during the adsorption is approximately $1 \mathrm{kPa}$. During the desorption phase, the heating water is pumped through the beds. As a result, silica gel is heated, and the adsorbed water molecules evaporate. The released water vapor flows to the condenser, and the bed pressure increases to the condenser pressure. The bed pressure is $7.5 \mathrm{kPa}$ during the desorption cycles. As can be seen, there is a dependency between the phases that is related to the pressure and temperature distribution. Furthermore, the pressure in bed numbers one and two is very similar, so the beds could be regarded as one big bed. However, the beds are divided into two beds to allow changing the beds' configuration into the two-bed mode or three-bed mode, as mentioned in Section 2.1. Additionally, the working configuration of the beds in the three-bed mode can be changed, i.e., beds one and two work in parallel, while bed three works singularly, or bed one and three work in parallel, while bed two works singularly, or bed two and three work in parallel, while bed one works singularly. 


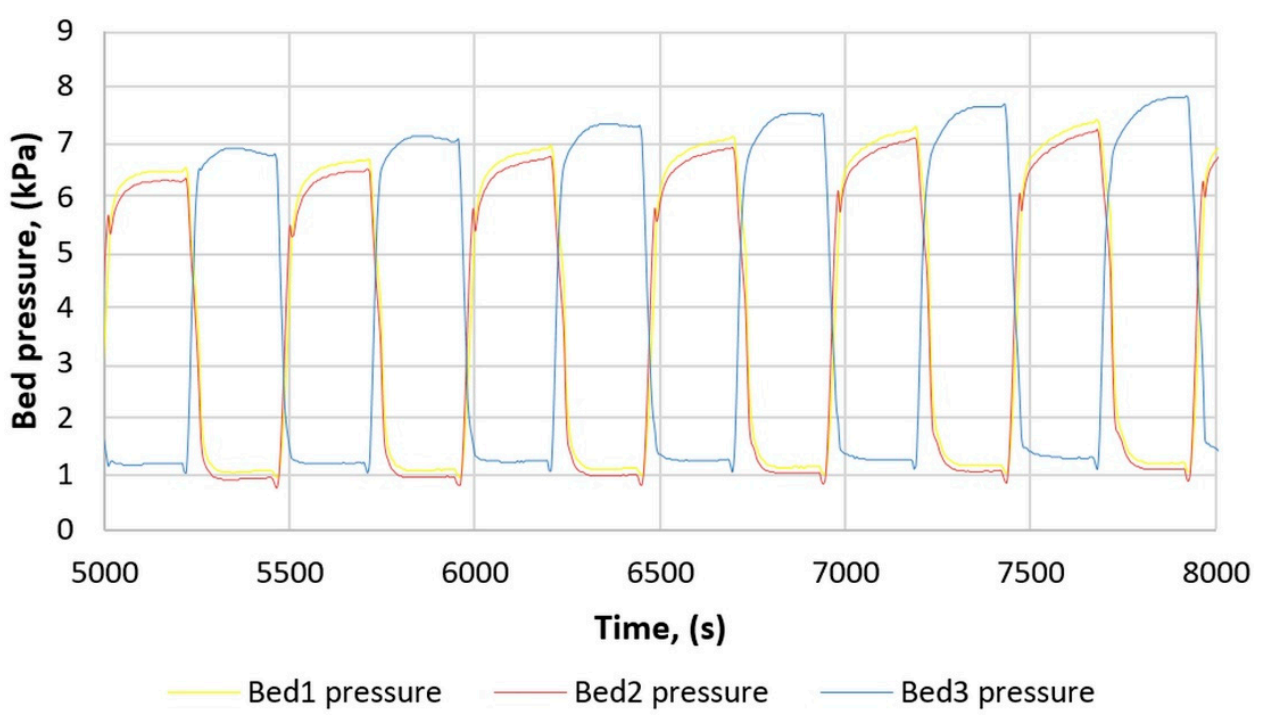

Figure 8. The changes in the pressure of beds in the function of time.

\section{Conclusions}

This paper deals with effective cooling and desalination technology, suitable for cleaner production and environmental conservation. It constitutes the first paper available in open literature dealing with the considered three-bed adsorption chiller with two beds working in parallel and one bed working individually, and the heating water's influence on its main operating parameters.

According to the obtained results, it can be concluded that the COP and SCP of the three-bed adsorption chiller are strongly dependent on the heating water temperature. When the heating water temperature increased from 57 to $85^{\circ} \mathrm{C}$, the COP increased from 0.20 to 0.58 (by $190 \%$ ). Therefore, increasing the heating water temperature results in an increase in the COP. Furthermore, SCP, which determines the cooling capacity obtained from $1 \mathrm{~kg}$ of the adsorbent, increases. As the heating water temperature increased from 57 to $85^{\circ} \mathrm{C}$, the SCP also increased from 27 to $160 \mathrm{~W} / \mathrm{kg}$. An increase in the heating water temperature accelerates the desorption process; thus, the silica gel's water adsorbed is released faster, and the chiller's cooling capacity rises.

The experimental studies show that the COP of the three-bed adsorption chiller is higher than the two-bed adsorption chiller, which was investigated in the previous work [26], by about $16 \%$ for the heating water temperature of $85^{\circ} \mathrm{C}$. However, the three-bed chillers' COP was lower compared to the two-bed chiller for the heating water temperature below $75^{\circ} \mathrm{C}$. Such a decline in the COP was caused by the slow heat transfer rate, and thus power shortage, especially in the evaporator.

In further studies, the authors are planning to investigate experimentally the performance of the three-bed chiller with alternately working beds, which may improve the chiller's COP, especially at low heating water temperatures.

Author Contributions: Conceptualization, K.S. and W.N.; methodology, K.S. and S.G.; formal analysis, K.S. and L.M.; investigation, W.K.; resources, W.K.; data curation, K.S.; writing-original draft preparation, K.S. and E.R.; writing-review and editing, E.R. and J.K.; supervision, S.G., W.N., J.K., and L.M.; project administration, K.S.; funding acquisition, L.M. and W.N. All authors have read and agreed to the published version of the manuscript.

Funding: This research was funded by a subsidy from the Faculty of Energy and Fuels AGH University of Science and Technology, number 16.16.210.476.

Conflicts of Interest: The authors declare no conflict of interest. 


\section{References}

1. Talus, K. European Union Energy. Available online: https://europa.eu/european-union/topics/energy_pl (accessed on 30 September 2020).

2. European Union, Paris Agreement. Available online: https://ec.europa.eu/clima/policies/international/ negotiations/paris_en (accessed on 30 September 2020).

3. Ministry of the Environment of the Republic of Poland United Nations Climate Change Conference COP19. Available online: http://www.cop19.gov.pl/ (accessed on 10 January 2020).

4. Ministry of Energy. Energy Statistics in 2016 and 2017; Statistics Poland: Warsaw, Poland, 2018.

5. Agencja Rynku Energii, S.A. Prognoza Zapotrzebowania Na Paliwa I Energię Do 2030 Roku; Ministerstwo Gospodarki: Warsaw, Poland, 2009.

6. Regulation (EU) No 517/2014 of the European Parliament and of the Council of 16 April 2014 on Fluorinated Greenhouse Gases and Repealing Regulation (EC) No 842/2006. Available online: https://eur-lex.europa.eu/ legal-content/EN/TXT/?uri=uriserv\%3AOJ.L_.2014.150.01.0195.01.POL (accessed on 10 January 2020).

7. Shmroukh, A.N.; Ali, A.H.H.; Ookawara, S. Adsorption working pairs for adsorption cooling chillers: A review based on adsorption capacity and environmental impact. Renew. Sustain. Energy Rev. 2015, 50, 445-456. [CrossRef]

8. Lee, J.G.; Bae, K.J.; Kwon, O.K. Performance investigation of a two-bed type adsorption chiller with various adsorbents. Energies 2020, 13, 2553. [CrossRef]

9. Sztekler, K.; Kalawa, W.; Stefanski, S.; Krzywanski, J.; Grabowska, K.; Sosnowski, M.; Nowak, W.; Makowski, M. Using adsorption chillers for utilising waste heat from power plants. Therm. Sci. 2019, 23, S1143-S1151. [CrossRef]

10. Huang, L.; Zheng, R.; Piontek, U. Installation and operation of a solar cooling and heating system incorporated with air-source heat pumps. Energies 2019, 12. [CrossRef]

11. Sah, R.P.; Choudhury, B.; Das, R.K. A review on adsorption cooling systems with silica gel and carbon as adsorbents. Renew. Sustain. Energy Rev. 2015, 45, 123-134. [CrossRef]

12. Yu, F.W.; Chan, K.T.; Sit, R.K.Y.; Yang, J. Review of standards for energy performance of chiller systems serving commercial buildings. Energy Procedia 2014, 61, 2778-2782. [CrossRef]

13. Shabir, F.; Sultan, M.; Niaz, Y.; Usman, M.; Ibrahim, S.M.; Feng, Y.; Naik, B.K.; Nasir, A.; Ali, I. Steady-state investigation of carbon-based adsorbent-adsorbate pairs for heat transformation application. Sustainability 2020, 12. [CrossRef]

14. Uyun, A.S.; Miyazaki, T.; Ueda, Y.; Akisawa, A. High performance cascading adsorption refrigeration cycle with internal heat recovery driven by a low grade heat source temperature. Energies 2009, 2, 1170-1191. [CrossRef]

15. Chorowski, M.; Pyrka, P.; Rogala, Z.; Czuprynski, P. Experimental study of performance improvement of 3-bed and 2-evaporator adsorption chiller by control optimization. Energies 2019, 12. [CrossRef]

16. Rouf, R.A.; Jahan, N.; Alam, K.C.A.; Sultan, A.A.; Saha, B.B.; Saha, S.C. Improved cooling capacity of a solar heat driven adsorption chiller. Case Stud. Therm. Eng. 2020, 17, 100568. [CrossRef]

17. Krzywanski, J.; Grabowska, K.; Sosnowski, M.; Zylka, A.; Sztekler, K.; Kalawa, W.; Wojcik, T.; Nowak, W. An adaptive neuro-fuzzy model of a re-heat two-stage Adsorption Chiller. Therm. Sci. 2019, 23, S1053-S1063. [CrossRef]

18. Stefański, S.; Mika, Ł.; Sztekler, K.; Kalawa, W.; Lis, Ł.; Nowak, W. Adsorption bed configurations for adsorption cooling application. In Proceedings of the E3S Web of Conferences Energy and Fuels, Krakow, Poland, 19-21 September 2018.

19. Gwadera, M.; Kupiec, K. Adsorpcyjne układy chłodnicze. Inżynieria Apar. Chem. 2011, 5, 38-39.

20. Pan, Q.; Peng, J.; Wang, R. Experimental study of an adsorption chiller for extra low temperature waste heat utilization. Appl. Therm. Eng. 2019, 163, 114341. [CrossRef]

21. Woo, S.Y.; Lee, H.S.; Ji, H.; Moon, D.S.; Kim, Y.D. Silica gel-based adsorption cooling cum desalination system: Focus on brine salinity, operating pressure, and its effect on performance. Desalination 2019, 467, 136-146. [CrossRef]

22. Kim, Y.D.; Thu, K.; Masry, M.E.; Ng, K.C. Water quality assessment of solar-assisted adsorption desalination cycle. Desalination 2014, 344, 144-151. [CrossRef] 
23. Saha, B.B.; Koyama, S.; Lee, J.B.; Kuwahara, K.; Alam, K.C.A.; Hamamoto, Y.; Akisawa, A.; Kashiwagi, T. Performance evaluation of a low-temperature waste heat driven multi-bed adsorption chiller. Int. J. Multiph. Flow 2003, 29, 1249-1263. [CrossRef]

24. Chorowski, M.; Pyrka, P. Modelling and experimental investigation of an adsorption chiller using low-temperature heat from cogeneration. Energy 2015, 92, 221-229. [CrossRef]

25. Chua, H.T.; Ng, K.C.; Malek, A.; Kashiwagi, T.; Akisawa, A.; Saha, B.B. Multi-bed regenerative adsorption chiller-Improving the utilization of waste heat and reducing the chilled water outlet temperature fluctuation. Int. J. Refrig. 2001, 24, 124-136. [CrossRef]

26. Sztekler, K.; Kalawa, W.; Nowak, W.; Mika, L.; Grabowska, K.; Krzywanski, J.; Sosnowski, M.; Al-Harbi, A.A. Performance evaluation of a single-stage two-bed adsorption chiller with desalination function. J. Energy Resour. Technol. 2020, 1-22. [CrossRef]

Publisher's Note: MDPI stays neutral with regard to jurisdictional claims in published maps and institutional affiliations.

(C) 2020 by the authors. Licensee MDPI, Basel, Switzerland. This article is an open access article distributed under the terms and conditions of the Creative Commons Attribution (CC BY) license (http://creativecommons.org/licenses/by/4.0/). 